\title{
Hidden treasures: Bologna's Poggi Palace
}

The exquisite obstetrics models on show in an Italian palace hint at its former multidisciplinary glories. Alison Abbott investigates the museum that was once home to a revolutionary institute of sciences.

Anatomy and art have depended on each other since the Renaissance. The bond took a new form in the eighteenth century with the development of anatomical models. Designed for teaching, as an alternative to inconvenient and infrequent cadaver dissection, these models represented the living, not the dead. They celebrated the beauty of human anatomy from the inside.

The models first emerged from studios in Bologna, Italy. Dignified, skinless men stood proud like three-dimensional versions of the Renaissance drawings of Andreas Vesalius. Models of voluptuous young women were draped provocatively on soft folds of wax-stiffened silk, the better to expose their innards to generations of medical students. Later models had more specialized functions, such as the fine obstetrics tableaux of modeller Anna MorandiManzolini (1716-1774), which showed pathological states for the first time.

Bologna, 290 kilometres north of Rome, is home to Europe's oldest university. For one magnificent century, it was also home to the Institute of Sciences, founded in 1711 by the army general and scholar Luigi Ferdinando Marsili, who regretted the failure of his university to engage in experimental research. His solution was to found the institute, which brought together all of the burgeoning sciences that the region offered - from anatomy and geology to astronomy and the study of electricity - in the frescoed sixteenth-century Poggi Palace on the outskirts of town. Marsili donated his own extensive scientific collection, gathered during his military travels, to the new institute. He generously equipped six laboratories and added a formidable astronomical tower to the palace. Interdisciplinary approaches would yield the greatest scientific advances, he reasoned.

His endeavour gained the crucial support of the Bolognese archbishop who, in 1740, became Pope Benedict XIV. The enlightened Benedict XIV believed that scientific discoveries would illustrate rather than diminish God's greatness. He exempted the institute's library from adherence to the Catholic Church's notorious list of prohibited books. In 1742, he commissioned and paid for artist Ercole Lelli to produce a series of life-sized wax models for the institute, to demonstrate different layers of muscle on the skeleton. A new era of scientific modelling was born.

Until the eighteenth century, obstetrics was

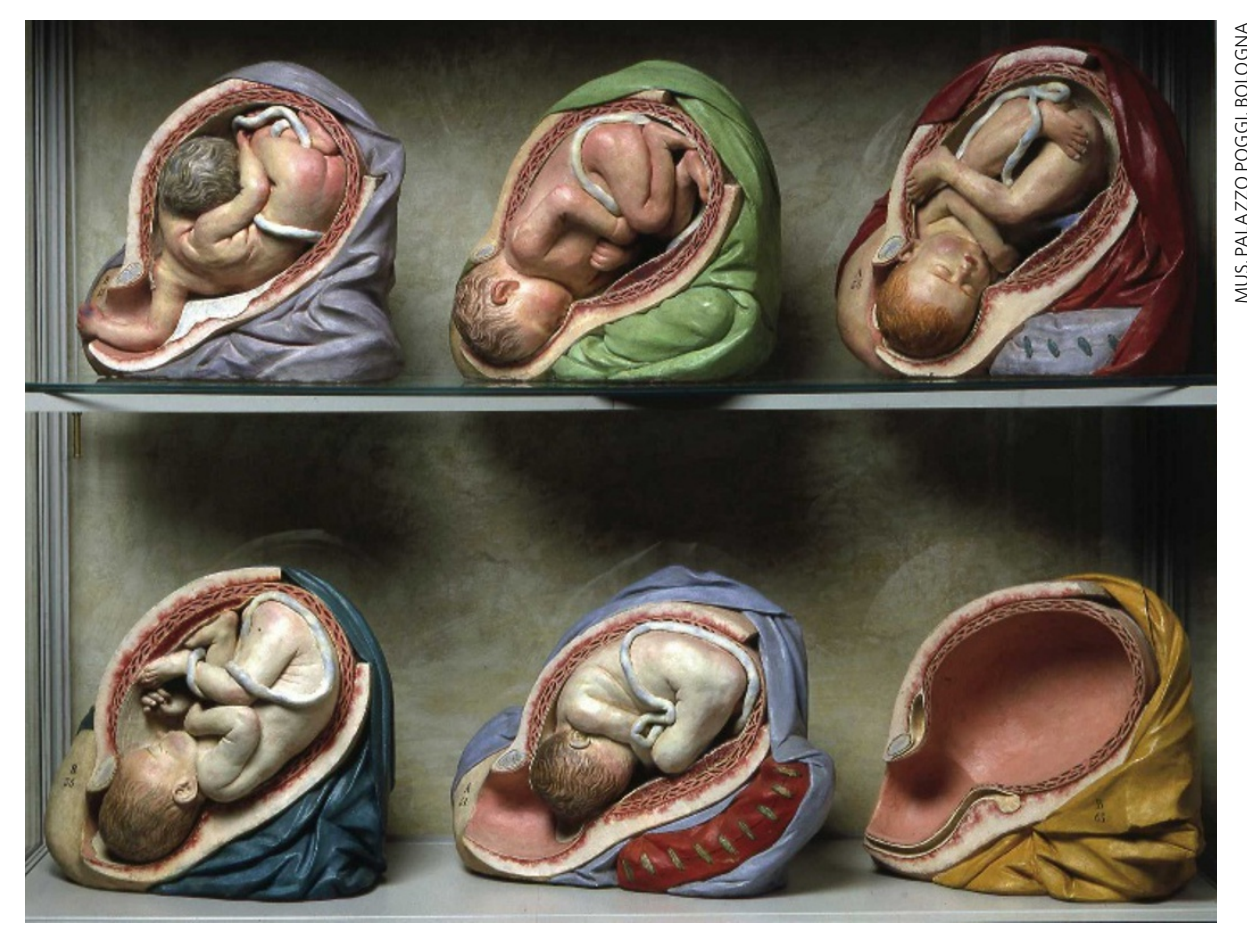

almost exclusively the domain of midwives. Then, new instrumentation - forceps to pull out a baby without damaging its head, hooks to turn it in the womb, and macabre instruments to extract dead babies - brought childbirth into the domain of men. Naturally, the instruments demanded a better knowledge of the topology and anatomy of the stages of birth.

This prompted the obstetrician Giovanni Antonio Galli to build up a private teaching collection of models, with the help of Lelli's students. He commissioned Morandi-Manzolini to make her precise wax tableaux. Many other items were made of clay, a cheaper material. One major series (pictured) allowed medical students and midwives to view or, when blindfolded, to feel the different phases of pregnancy through to delivery. Some models demonstrated difficult and potentially deadly fetal positions, such as breach or tangled in the umbilical cord.

In 1757, Benedict XIV bought the entire collection of 170 models and donated it to the institute's school of surgery, appointing Galli to teach obstetrics. Midwives had to enter the school through a back door. When Galli died in 1782, Luigi Galvani - better known for discovering the electricity generated in animal muscles and nerves, and already president of the institute - took over his position. Galvani also proposed the correct notion that uterine contractions during labour have a strong nervous component.

Galvani was dismissed from all of his posts in 1797 after he refused to swear an oath of allegiance to the occupying napoleonic troops. He died in poverty the next year. During the university reforms that Napoleon enforced in the early nineteenth century, the holdings and equipment of the institute were dispersed.

In the past decade, many of the original collections and instruments, including the anatomy and obstetrics models, have been tracked down and restored to their original rooms in the Poggi Palace, which opened again in 2000. Among the many exhibits, visitors will find the lab where Galvani did his famous experiments on frogs and Ulisse Aldrovandi's sixteenthcentury natural history collection, which went against the trend of the randomly organized Wunderkammer, or cabinets of curiosity. Alison Abbott is Nature's Senior European Correspondent.

See www.museopalazzopoggi.unibo.it for further details. For more Hidden treasures see www. nature.com/nature/focus/hiddentreasures 